\title{
GI-MS45-04 | How, and When, to Effect Collaborations
}

Helliwell, John (University of Manchester, Manchester, GBR)

It is a major possibility that at some stage of your scientific career you will wish to take on a project of such wide scope, or respond to an invitation to join such a project as a partner, that collaboration is the way forward. Funding agencies also have recognised this, and there are many schemes and variants of scale of collaboration for you to choose from. One overriding principle to keep in sight of is the compatibility of your potential collaborator. An aspect that will perhaps cause the most diverse of behaviours from your collaborators will be the publications that result from your collaborations. I will draw on examples from my recent book [1] and from my research career.

[1] John R Helliwell (2017) “Skills for a Scientific Life” published by CRC Press, Taylor and Francis Group 